\title{
Glete de Alcântara: legado centenario de la enfermería brasileña*
}

\author{
Glete de Alcântara: centenary legacy of brazilian \\ nursing \\ Glete de Alcântara: legado centenário da enfermagem \\ brasileira
}

\begin{abstract}
Luciana Barizon Luchesi ${ }^{1}$, Emiliane Silva Santiago ${ }^{2}$, Taka Oguisso ${ }^{3}$
*Os resultados do presente artigo compõem um recorte do estudo intitulado Origens da Escola de Enfermagem de Ribeirão Preto, sob a ótica de Glete de Alcântara, o qual teve financiamento da FAPESP, de 2009 a 2011, Processo 2008/10170-2

1 Professora Doutora da Escola de Enfermagem de Ribeirão Preto da Universidade de São Paulo (USP), Brasil, 1. ${ }^{-}$vice-presidente da Academia Brasileira de História da Enfermagem (ABRADHENF), de 2016 a 2018 (www.abradhenf.com.br). Líder do Grupo de Pesquisa Laboratório de Estudos em História da Enfermagem (LAESHE) (www2.eerp.usp.br/laeshe). Correo electrónico: luchesi@eerp.usp.br.

${ }^{2}$ Professora Doutora da Universidade Federal do Mato Grosso (UFMT), Campus Sinop, Brasil. Líder do Grupo de Pesquisa em História da Enfermagem e Saúde (GPHEnfS). Membro do Grupo de Pesquisa Laboratório de Estudos em História da Enfermagem (LAESHE) e da diretoria da Academia Brasileira de História da Enfermagem (ABRADHENF). Correo electrónico: emilianesant@gmail.com.

${ }^{3}$ Professora Titular da Escola de Enfermagem da Universidade de São Paulo (EE-USP), Brasil. Acadêmica da Academia Brasileira de História da Enfermagem (ABRADHENF). Correo electrónico: takaoguisso@uol.com.br

Cómo citar este artículo en edición digital: Luchesi, L.B., Santiago, E.S. E Oguisso, T. (2019). Glete de Alcântara: legado centenario de la enfermería brasileña. Cultura de los Cuidados (Edición digital), 23(53). Recuperado de http://dx.doi.org/10.14198/cuid.2019.53.10
\end{abstract}

Correspondencia: Taka Oguisso. Escola de Enfermagem de Ribeirão Preto, Avenida Bandeirantes, $n$. 3900, Campus USP, Bairro Monte Alegre, Ribeirão Preto, SP, Brasil. CEP 14040-902

Correo de contacto: luchesi@eerp.usp.br

Recibido: 20/11/2018; Aceptado: 11/02/2019

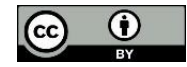

\section{ABSTRACT}

The aim was to identify relevant points in the bibliography of the Brazilian nurse Glete de Alcântara. It is a historical study of biography, which used documentary analysis. A vast documentary corpus was located, with emphasis on her memorial (1963 résumé), 54 publications, as well as articles and books mentioning her career. Through the Rockefeller Foundation, she graduated as a nurse at the University of Toronto-Canada. She initially taught at the
University of São Paulo's School of Nursing, Brazil, received her BS degree in Social Sciences, at the same university and with a grant from the Kellogg Foundation, in 1951, obtained a Master of Arts degree from Teachers College, Columbia University, New York. In 1952 she was chosen to create and manage the University of São Paulo at Ribeirão Preto College of Nursing, where she remained for almost two decades as its dean. Her outstanding performance as president of the Brazilian Nursing 
Association, only ended with her death in 1974, while in the second term as national president of the entity, where she contributed to the scientific and legal advancement of Brazilian nursing. As a leadership model and dedication for the Nursing class Glete de Alcântara has left a great legacy of struggle for Nursing.

Keywords: Nursing, nursing history, nursing schools, nursing societies, biography.

\section{RESUMO}

Objetivou-se identificar pontos relevantes na bibliografia da enfermeira brasileira Glete de Alcântara. Trata-se de estudo histórico de biografia, em que se utilizou análise documental. Localizou-se vasto corpus documental, com destaque para seu memorial (currículo de 1963), 54 publicações, além de artigos e livros com menção à sua carreira. Por meio da Fundação Rockefeller, graduou-se enfermeira na Universidade de Toronto, Canadá. Lecionou inicialmente na atual Escola de Enfermagem da Universidade de São Paulo, Brasil; fez Licenciatura em Ciências Sociais na mesma universidade; com bolsa da Fundação Kellogg, em 1951, obteve o grau de Master of Arts, no Teachers College, da Universidade Columbia, New York; foi indicada para criar e dirigir a Escola de Enfermagem de Ribeirão Preto, onde permaneceu por quase duas décadas como diretora. Sua atuação marcante na Associação Brasileira de Enfermagem só findou com sua morte, em 1974, enquanto estava no segundo mandato como presidente nacional da entidade, onde contribuiu para o avanço científico e legal da enfermagem brasileira. Modelo de liderança e dedicação à classe da Enfermagem, Glete de Alcântara deixou um grande legado de luta em prol da Enfermagem.
Palavras chave: Enfermagem, história da enfermagem, escolas de enfermagem, sociedades de enfermagem, biografia.

\section{RESUMEN}

Se objetivó identificar puntos relevantes en la bibliografía de la enfermera brasileña Glete de Alcántara. Se trata de un estudio histórico de biografía, que utilizó análisis documental. Se localizó vasto corpus documental, con destaque para su memorial (currículo de 1963), 54 publicaciones, además de artículos y libros que mencionan su carrera. A través de la Fundación Rockefeller, se graduó enfermera en la Universidad de Toronto-Canadá. Fue profesora en la Universidad de São Paulo, Brasil, licenció en Ciencias Sociales, en la misma universidad y con beca de la Fundación Kellogg, en 1951, obtuvo el grado de Master of Arts, en el Teachers College, de la Universidad de Columbia, Nueva York. En 1952 fue indicada para crear y dirigir la Escuela de Enfermería de Ribeirão Preto, donde permaneció por casi dos décadas como directora. Su actuación excelente en la Asociación Brasileña de Enfermería, sólo se terminó con su muerte, en 1974, mientras estaba en el segundo mandato de presidenta nacional de la entidad, donde contribuyó al avance científico y legal de la enfermería brasileña. Como modelo de liderazgo y dedicación a la clase Glete de Alcántara deja un gran legado de lucha en pro de la Enfermería.

Palabras clave: Enfermería, historia de la enfermería, escuelas de enfermería, sociedades de enfermería, biografía. 


\section{PRÓLOGO}

Estudar o legado deixado pela Prof. a Glete de Alcântara constitui árdua tarefa, visto que, em mais de 12 anos de estudos realizados no âmbito do Laboratório de Estudos em História da Enfermagem (LAESHE) sobre sua carreira e obra acadêmica, paira a ideia da impossibilidade de compreender toda a dimensão de seus trabalhos, considerando sua atuação em muitos âmbitos da enfermagem: desde o ensino, a pesquisa, a extensão e a gestão institucional até o campo político, em nível nacional e internacional. Da mesma maneira, é difícil compreender as influências internacionais envolvidas, uma vez que sua formação na graduação, como enfermeira, e sua pós-graduação foram realizadas no exterior.Faz-se inviável também tratar da memória dessa enfermeira sem mencionar sua profícua trajetória dentro da Escola de Enfermagem de Ribeirão Preto da Universidade de São Paulo (EERP-USP), instituição que ela criou e dirigiu por quase duas décadas; poder-seia mesmo denominar como a "grande casa" de Glete de Alcântara, o lugar em que ela dedicou seus maiores esforços e também alcançou as maiores conquistas acadêmicas, como a defesa da primeira tese de cátedra da América Latina por um enfermeiro.

No presente estudo tem-se como objetivo identificar pontos relevantes na bibliografia da Prof. ${ }^{a}$ Glete de Alcântara, por meio da análise documental. A pesquisa teve início em 2008, analisando diferentes perspectivas da carreira e o impacto das suas ações que, por sua extensiva massa documental, ainda se encontra em andamento. Nesse sentido, são apresentados os resultados da conclusão da primeira etapa do estudo, os quais compõem a análise documental de sua biografia.

\section{MÉTODO}

Trata-se de estudo biográfico, de perspectiva histórica, em que se utilizou da análise documental como perspectiva analítica. A palavra biografia, em sua origem grega $\beta$ ro $\rho \alpha \varphi \varphi^{\alpha} \alpha$, possui significado que pode ser traduzido como "escrever a vida" (Sanna, 2011). A biografia histórica deve ser, em certo grau, a narração de uma vida articulada a eventos individuais e coletivos. Por isso é mais fácil retratar a vida de grandes homens que do homem comum. Muitas têm resultado em retorno às biografias tradicionais, superficiais. Uma biografia verdadeira só é legitimada quando se respeita esse objetivo: apresentar e explicar a vida de uma pessoa dentro da história (Le Goff, 1989).

O presente projeto recebeu aprovação do Comitê de Ética em Pesquisa (CEP) da EERP-USP, em 2008, Protocolo n. . $^{-}$ 0970/2008. Os locais de pesquisa foram os arquivos da Universidade de São Paulo (USP) e suas duas escolas de Enfermagem, a EERP-USP e a Escola de Enfermagem da USP (EE-USP), situadas, respectivamente, em Ribeirão Preto e em São Paulo, ambas as cidades localizadas no Estado de São Paulo. Como fontes foram utilizados artigos, livros, teses, relatos publicados e outros materiais. Nesse sentido, foi utilizada a análise documental, que explicita técnicas para representação do documento de forma condensada para armazenamento e consulta, operando por classificação e indexação (Bardin, 2011).

\section{RESULTADOS E DISCUSSÃO}

Durante a busca e análise documental, foi localizado um vasto corpus documental. A considerável produção da Prof. ${ }^{a}$ Glete de Alcântara mostra a dimensão de seu engajamento com a profissão. A fonte mais 
completa sobre a trajetória da docente foi localizada em seu memorial (currículo), produzido em 1963, como exigência para a defesa de concurso de cátedra, no qual a docente relata de forma breve (16 páginas) sua formação, desde o secundário até 1963, atividades didáticas e de gestão, formação científica e atividades de organização e desenvolvimento de centros/núcleos de ensino e pesquisa, títulos universitários, eventos dos quais participou e trabalhos publicados (Alcântara, 1963a). Entretanto, observou-se que algumas de suas produções não estão citadas no referido memorial.

Outra obra localizada que contribuiu para a compreensão de partes da vida dessa enfermeira ocorreu dois meses após a morte da docente, quando a EERP-USP e a Associação Brasileira de Enfermagem (ABEn), Distrito de Ribeirão Preto, organizaram a Semana de Estudos Professora Doutora Glete de Alcântara, cuja intenção não teria sido homenagem póstuma, mas, sim, demonstrar a permanência da docente e de sua obra para a instituição e para os participantes. O evento em questão deu origem ao livro Glete de Alcântara: vida e obra, organizado por duas ex-alunas dela, as quais se tornaram docentes na EERP-USP. A obra é constituída de relatos pessoais de amigos e colegas que conviveram com a mesma no âmbito do trabalho e fora dele (Angerami y Pelá, 1976). Além disso, outra ex-aluna, pesquisadora na área de História da Enfermagem, dedicou um pequeno capítulo à sua memória no livro Enfermeiras do Brasil: histórias de pioneiras (Secaf y Costa, 2007).

Em relação à produção científica da docente, foram localizados 54 textos, algo considerado imponente para a época. Das produções localizadas, a maioria foi concretizada na década de 1960 (21), seguida das décadas de 1950 (18), 1940 (9) e 1970 (6).
Do total, 37 textos foram publicados na Revista Brasileira de Enfermagem (REBEn), seguidos da Revista Paulista de Hospitais (4), Boletín de la Oficina Sanitaria Panamericana (2) e Revista da Escola de Enfermagem da USP (2). Além disso, houve uma publicação na Organização PanAmericana de Saúde (OPAS), Organização Mundial da Saúde (OMS), The American Journal of Nursing, Ministério da Educação (MEC; Brasil) e Fundação Carlos Chagas.

Em relação ao conteúdo da produção, foram 23 artigos, sendo 3 internacionais, relatórios de suas atividades na ABEn (6), análises de livros internacionais (4), resumos de artigos internacionais (2), discursos (2), aulas inaugurais (2), traduções de artigos na íntegra (2) e folhetos (2). Destaca-se, ainda, seu memorial, tese de cátedra, livro, colaboração em relatório internacional, colaboração em tradução de livro, resumo de relatório internacional, capítulo de livro, currículo, conferência, resumo de tese e mensagem da presidente, os quais tiveram uma produção cada. Grande parte das publicações estão concentradas na REBEn, que nasceu com o nome de Annaes de Enfermagem (1932), mudando para Anais de Enfermagem (década de 1940) e, posteriormente, Revista Brasileira de Enfermagem (REBEn; 1954).

Destaca-se que algumas produções da docente foram replicadas em outros locais, como, por exemplo, o artigo intitulado Currículo de Escolas de EnfermagemIntegração da Escola de Enfermagem na sociedade, publicado na revista Anais de Enfermagem, em 1952 (Alcântara, 1952), reproduzido na Revista Paulista de Hospitais, no ano 1954 (Alcântara, 1954), e traduzido para o espanhol com o título Integración de la escuela de enfermería en la colectividad, no Boletín de la Oficina Sanitaria Panamericana, em 1953 (Alcântara, 1953). 
Assim como sua colaboração na tradução para o português do livro Enfermagem para o futuro (relatório preparado para o Conselho Nacional de Enfermagem dos Estados Unidos da América-EUA), de Esther Lucille Brown, traduzido em parceria com Maria Rosa de Sousa Pinheiro e Maria de Lourdes Verderese, em 1949 (Brown, 1949) e a publicação Programa de base para una formación completa de la enfermera, de 1962, no Cadernos de Saúde Pública, da OMS, recebeu traduções para o francês, inglês e russo (Alcântara, 1962a).

Na produção científica, foram localizados dois textos em que são abordados aspectos de sua vida ou obra (Mendes, Leite, Leite y Trevizan, 2002; Pinheiro, 1975), além de apresentações de trabalhos não publicados e o discurso da Prof. ${ }^{a}$ Dr. ${ }^{\text {a }}$ Taka Oguisso durante a mesa-redonda Convivências e lembranças da Prof..$^{\text {a }}$ Dr..$^{\text {a }}$ Glete de Alcântara, nas comemorações de seu centenário de nascimento, em novembro de 2010, realizado na EERP-USP (Oguisso, 2010). A Prof. ${ }^{\text {a }}$ Dr. ${ }^{\text {a }}$ Taka Oguisso trabalhou diretamente, como 1. a tesoureira (19721976), com a Prof. a Glete de Alcântara, quando esta era presidente da ABEnnacional, e, também, na EE-USP, no Departamento de Orientação Profissional.

Foram também localizadas as atas do Conselho Universitário da USP e as Atas do corpo docente, de 1948 a 1953, da Escola de Enfermagem de São Paulo, da Faculdade de Medicina, da Universidade de São Paulo (EEFMUSP). Essa última foi a pasta mais antiga encontrada na Diretoria Acadêmica da instituição. As atas estão datilografadas em papel timbrado e assinadas por Helena de Barros Silveira, secretária. A EE-USP gentilmente permitiu a análise das atas, em 2010. A partir dos documentos mencionados, foi possível levantar parte importante da biografia da docente.

\section{Glete de Alcântara antes da Enfermagem}

Glete de Alcântara nasceu em Minas Gerais, em 1910, na cidade de São Sebastião do Paraíso, filha de José Proença de Alcântara e Maria Pimenta de Alcântara (Alcântara, 1963a), primogênita de dez filhos (seis mulheres e quatro homens), aprendeu desde cedo a importância do cuidado, pois, com a morte da mãe, cumpriu a promessa de tornar-se responsável pela educação de seus irmãos (Ferreira-Santos, 1976).

Glete de Alcântara diplomou-se em 1928, pela Escola Normal da Praça da República, posteriormente denominada Instituto de Educação Caetano de Campos. Ela menciona que exerceu o magistério primário por algum tempo, mas não especifica o período. Sua formação a colocava entre um grupo minoritário de mulheres alfabetizadas e que chegavam ao nível do atual ensino médio no Brasil (Alcântara, 1963a).

Segundo o censo de 1940, 56,8\% dos brasileiros maiores de dez anos eram analfabetos, sendo que os índices de alfabetização do gênero masculino superavam em muito os do gênero feminino em todo o Brasil. No Estado de São Paulo, onde se encontrava Glete de Alcântara, o índice de alfabetização era de $41,9 \%$, sendo $58,4 \%$ homens e $45,7 \%$ mulheres (Instituto Brasileiro de Geografia e Estatística [IBGE], 2000).

Em 1930, ela concluiu o curso de educadora sanitária, no Instituto de Hygiene da USP, atual Faculdade de Saúde Pública da USP (Alcântara, 1963a). Essa instituição foi responsável pela aproximação entre Maria Rosa de Sousa Pinheiro e Glete de Alcântara, relação essa descrita em discurso publicado, em razão da outorga do "Prêmio Enfermeira Paulista", do Governo do Estado 
de São Paulo, Brasil, durante a Sessão de Instalação da Semana de Enfermagem de 1970, organizada pela ABEn, Seção de São Paulo (ABEn-SP). Coube a Alcântara discursar sobre a homenageada Maria Rosa de S. Pinheiro (Alcântara, 1970).

$\mathrm{Na}$ Escola Normal, ambas se conheceram pela amizade que Glete de Alcântara tinha com uma irmã de Maria Rosa de S. Pinheiro. Posteriormente, ficaram mais unidas ao frequentarem o curso de Educadora Sanitária e, depois, trabalhando juntas no Serviço de Saúde Escolar, da Secretaria de Saúde da Prefeitura de São Paulo (Alcântara, 1970).

\section{IMAGEM 1. Glete de Alcântara durante o curso de graduação em Enfermagem, no Canadá, de 1941-1944}

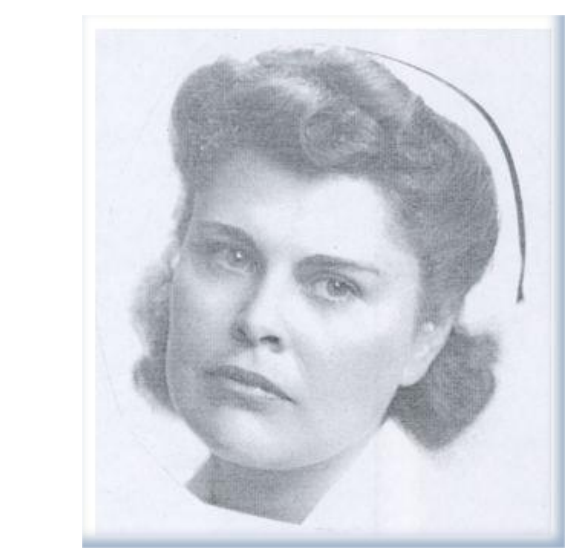

Imagem gentilmente cedida pela Lawrence S. Bloomberg Faculty of Nursing, Arquivo da Universidade de Toronto, pela diretora da instituição, em 2009, Sioban Nelson, RN,

$\mathrm{PhD}$, FAAN, FCAHS, para propósitos de pesquisa

\section{Glete de Alcântara antes da Enfermagem}

Em 1940, a Fundação Rockefeller enviou a enfermeira Mary Elizabeth Tennant para dar início às discussões da criação de uma escola de enfermagem que viria a ser a atual Escola de Enfermagem da USP (EE-USP), em cumprimento à clausula de convênio firmado, em 1925, entre o Governo do
Estado de São Paulo, Brasil, e a Fundação Rockefeller. A Escola de Enfermagem seria uma das contrapartidas ao financiamento recebido para a construção e dotação de equipamentos da Faculdade de Medicina (FM-USP) (Carvalho, 1980). Houve intermediação do diretor do Instituto de Hygiene (IH-USP), Dr. Geraldo de Paula Souza, e do Interventor do Estado de São Paulo, Adhemar de Barros, decidindo-se pela criação de uma escola intitulada inicialmente Escola de Enfermagem de São Paulo, da Faculdade de Medicina, da Universidade de São Paulo (EEFMUSP), e, posteriormente, EE-USP, com contribuição do governo e da Fundação Rockefeller (Carvalho, 1980).

Para a organização da futura escola era preciso um corpo docente devidamente preparado. A Fundação Rockefeller se dispôs a conceder bolsas de estudo para que educadoras sanitárias pudessem adquirir formação em enfermagem, na América do Norte. A escolha das primeiras bolsistas ficou sob a responsabilidade do Dr. Geraldo de Paula Souza (Pinheiro, 1976), que selecionou Maria Rosa S. Pinheiro, que, na época, era educadora chefe do IH-USP, e Zilda de Carvalho, que trabalhava no mesmo instituto, para início em 1940 (Alcântara, 1970; Pinheiro, 1976). Para as bolsas do ano seguinte, Maria Rosa S. Pinheiro sugeriu a inclusão do nome de Glete de Alcântara, o que foi aceito de pronto, e de Lucia Jardim, que também trabalhava no IH-USP, para o ano 1941 (Alcântara, 1970).

Nesse contexto, as quatro educadoras sanitárias iniciariam o curso de Enfermagem na Universidade de Toronto. O registro dos motivos que levaram à escolha da Universidade de Toronto, no Canadá, pela Fundação Rockefeller, uma organização tipicamente americana, para encaminhar 
bolsistas brasileiras, recupera, ainda que hipoteticamente, os trabalhos de Edith de Magalhães Fraenkel, convidada pela Fundação Rockefeller para organizar e dirigir a EEFMUSP, momento em que a mesma foi subsidiada para visitar escolas americanas e canadenses, como as escolas da Philadelphia e de Toronto, o que permite tal inferência.

Glete de Alcântara descreve a cidade de Toronto como uma típica cidade nórdica, com arquitetura austera e inverno infindável, com padrões culturais muito diferentes dos brasileiros: não era "uma cidade cheia de encantos". Ressalta que o período teria sido muito mais difícil se não fosse a presença de Maria Rosa de S. Pinheiro, que se tornara legítima líder do grupo das brasileiras (Alcântara, 1970). Com o início da participação dos Estados Unidos da América (EUA) na Segunda Guerra Mundial, todas as bolsas novas foram canceladas a partir de 1942, mantendo-se as que já estavam em curso (Pinheiro, 1976).

\section{Atuação na Escola de Enfermagem da USP}

Ao retornar ao Brasil, concluído o curso de Enfermagem Geral e Enfermagem de Saúde Pública, em 1944, Glete de Alcântara revalidou seu diploma na Escola de Enfermagem Anna Nery (UFRJ) e engajouse na EEFMUSP, que já havia começado a funcionar. Para tal foi contratada como professora de Técnica de Enfermagem, entre 1945 e 1952 -a docente menciona ter ampliado os objetivos e trocado o nome para Introdução à Enfermagem. Ela ministrou também Enfermagem Médica, de 1945 a 1947 (Alcântara, 1963a).

No mesmo período, ela buscou ampliar sua formação, obtendo os títulos de Licenciada em Ciências Sociais, pela Faculdade de Filosofia, Ciências e Letras da
USP. Além disso, recebeu bolsa de estudos da Fundação Kellogg para os EUA, de setembro de 1950 a agosto de 1951, onde obteve o grau de Master of Arts, no Teachers College, da Universidade Columbia, New York (Alcântara, 1964; Alcântara, 1963a).

Em relação às Atas do corpo docente, de 1948 a 1953, da EEFMUSP, a mais antiga é datada de 23 de setembro de 1948 e contou com a presença de 12 docentes, inclusive a diretora, Edith de Magalhães Fraenkel, que presidia algumas dessas reuniões, pois, ao final, era designada uma das professoras para presidir a reunião seguinte -uma maneira didática e prática de treinar, dar oportunidade às docentes de presidir e liderar (Atas Escola de Enfermagem da USP, 1953). A Prof. a Glete de Alcântara estava presente em quase todas as reuniões, que tinham periodicidade quinzenal e, algumas vezes, semanal.

Em 1951, a Comissão de Ensino, do Regimento da USP, apresentou ao Conselho Universitário o relatório sobre a instalação de uma segunda Faculdade de Medicina na USP, a Faculdade de Medicina de Ribeirão Preto (FMRP-USP), documento no qual menciona a necessidade de inclusão de uma Escola de Enfermagem anexa, pois a enfermagem constituía fator decisivo para o bom funcionamento hospitalar (Universidade de São Paulo, 1951).

\section{A Escola de Enfermagem de Ribeirão Preto da USP}

Em dezembro de 1951, foi criada a FMRPUSP e, anexa a ela, a Escola de Enfermagem de Ribeirão Preto (EERP-USP). A Ata do Conselho Universitário da USP, em sua 312. Sessão do Conselho Universitário, de 5 de março de 1952, destaca que o Dr. Zeferino Vaz (1908-1981), primeiro Diretor da FMRPUSP, por indicação do Prof. Dr. Paulo César de Azevedo Antunes, convidou a Prof. ${ }^{\text {a }}$ 
Glete de Alcântara para organizar e dirigir a nova Escola de Enfermagem.

Em artigo, a Prof. ${ }^{a}$ Glete de Alcântara defendeu como "inovações" da EERP-USP a necessidade de ensinar as ciências sociais articulada ao ensino da Enfermagem, assim como a importância de correlacionar os aspectos preventivos da Enfermagem a todas as disciplinas do curso e incluir o ensino teórico e prático de administração aplicada à enfermagem, de psicologia educacional e de didática (Alcântara, 1962b).

Ela abriu caminho para enfermeiros, docentes e pesquisadores de enfermagem, com sua tese de cátedra apresentada para concurso à cadeira n..$^{\circ}$ 4: História da Enfermagem e Ética (Aplicada à Enfermagem), intitulada A Enfermagem moderna como categoria profissional: obstáculos à sua expansão na sociedade (Alcântara, 1963b) -referência obrigatória em estudos sobre a pesquisa em Enfermagem no Brasil e História da Enfermagem, defendida em 1963. Foi pioneira não apenas no Brasil, mas em toda a América Latina.

Destaca-se que sua tese versou exatamente sobre História da Enfermagem, relevante tema cujo estudo contribui para a formação da identidade profissional e do comprometimento, que demarca uma linha de conduta, ações e atitudes para o campo técnico-assistencial, educação, pesquisa ou administração (Oguisso, 2014).

Em 1971, após 18 anos à frente da direção da EERP-USP, por força do Estatuto da USP, a Dr. ․ Glete de Alcântara, já com o título de professora catedrática (atual professor titular), teve que deixar o cargo de diretora, transferindo-o ao médico Prof. Dr. Jorge Armbrust Lima Figueiredo, tornando-se vice-diretora até sua aposentadoria, em 1972 (Mendes, 1993), quando retornou à sua instituição de origem, a EEUSP.

\section{Atividades na Associação Brasileira de Enfermagem}

Glete de Alcântara desenvolveu inúmeros trabalhos junto à atual ABEn, sobretudo para fomentar a publicação do órgão de divulgação, a Revista Brasileira de Enfermagem (REBEn), até hoje em circulação. Sua atuação teve início em 1946, quando foi nomeada Presidente da Comissão de Propaganda da REBEn e responsável pelos pedidos de assinatura, cujo trabalho é destacado em relatórios anuais. Tal fato rendeu-lhe o cargo de secretária da Revista, tendo Edith de Magalhães Fraenkel como diretora da mesma (Carvalho, 2008). Nesse período, observa-se a escalada política da Prof. ${ }^{a}$ Glete de Alcântara dentro da associação.

Em 1948, foi eleita presidente da primeira seção estadual da Associação Brasileira de Enfermeiras Diplomadas (ABED), em São Paulo, (criada em 1945) (Alcântara, 1964), sucedendo a primeira presidente, a Prof. ${ }^{\mathrm{a}}$ Edith de Magalhães Fraenkel (Carvalho, 2008), sendo reeleita para o período de 1950 a 1952.

Segundo Daisy Caroline Bridges, no livro sobre o Conselho Internacional de Enfermeiras (CIE), em relatório de 1949, a autora refere que o convite para que as reuniões do Conselho de Representantes Nacionais (CRN), órgão máximo de deliberação do CIE e $X$ Congresso Quadrienal, acontecessem no Brasil, em 1953, teria sido encaminhado pela ABED (atual ABEn) (Bridges, 1967).

É importante destacar também que Daisy Caroline Bridges veio ao Brasil em 1950, a convite da ABED, assistiu ao IV Congresso Nacional de Enfermagem, realizado na Bahia, e participou de discussão com a diretoria da ABED sobre os planos iniciais para o congresso de 1953, sendo a primeira vez que o CIE enviava um membro 
executivo à América do Sul. "Em agosto de 1951, houve uma reunião do Grande Conselho (nome antigo do CRN), em Bruxelas, quando o Brasil foi representado por Waleska Paixão, presidente da ABED, por Dulce Pontes (secretária executiva da ABED) e por Glete de Alcântara (vicepresidente da Comissão de Preparativos para o X Congresso Internacional). Glete de Alcântara havia sido convidada como hóspede oficial da Associação de Enfermeiras Suecas não apenas para visitar o país, mas para tomar conhecimento de como a conferência de 1949 havia sido organizada (Carvalho, 2008). A sugestão ao CIE para que o evento fosse realizado em julho de 1953, quando o "clima seria ameno semelhante ao do fim da primavera em países nórdicos" foi feita pela presidente Glete de Alcântara (Bridges, 1967).

Portanto, considerando o documentário sobre a história da ABEn, sua presidente nacional de 1948 a 1950 foi Edith de Magalhães Fraenkel que, de fato, foi quem encaminhou o convite para o CIE, em 1949. $\mathrm{Na}$ gestão seguinte, de 1950 a 1952, a presidente foi Waleska Paixão, que fez os preparativos para o evento internacional, com a colaboração de outras enfermeiras, sobretudo das que tinham domínio do inglês. Nesse período, a Prof. ${ }^{a}$ Glete de Alcântara, como presidente da Seção de São Paulo, da ABED, e vice-presidente da Comissão de Preparativos para o $X$ Congresso Internacional, deve ter colaborado muito no planejamento e preparação desse evento (Carvalho, 2008), que foi o primeiro desse porte no Hemisfério Sul e em um país da América Latina.

As reuniões do Conselho de Representantes Nacionais (CRN-CIE) foram realizadas no auditório da EE-USP, onde foi aprovado o primeiro Código de Ética da Enfermagem do mundo, até hoje existente, embora atualizado algumas vezes. Nesse congresso foram também admitidos sete novos membros ou associações nacionais (Bridges, 1967).

Glete de Alcântara foi a presidente da Comissão Executiva responsável por organizar o evento com mais de 1.300 participantes de 46 associações nacionais diferentes. O Congresso foi realizado no Hotel Quitandinha, em Petrópolis, Estado do Rio de Janeiro, Brasil, em julho de 1953. Houve planejamento, pela primeira vez, da interpretação simultânea em português, espanhol e inglês, sendo que as edições anteriores foram apenas em inglês, mas, pouco antes da abertura, o equipamento quebrou (Bridges, 1967).

O desconforto causado pelas baixas temperaturas naquele ano deve ter sido muito grande e inesquecível, pois esse fato foi mencionado em livro sobre a história desse Conselho, considerando que, no convite brasileiro, destacava-se o mês de julho para a realização do evento, pois o clima nessa região do Brasil seria parecido com o final de uma primavera europeia. As participantes foram obrigadas a usar as roupas mais quentes que haviam trazido, pequenos tapetes do hotel e garrafas cheias de água quente, para se aquecerem nas reuniões. Entretanto, os locais escolhidos foram considerados muito bons (Bridges, 1967).

Para as reuniões do CRN, todos os delegados oficiais, inclusive o staff do CIE, totalizando mais de 100 pessoas, foram hospedados na residência da EE-USP, aproveitando-se o período de férias das alunas (Bridges, 1967). Foi realmente um ato de coragem e ousadia muito grande sediar um evento dessa envergadura quando, no Brasil, na época, a ABED contava apenas com algumas centenas de associados.

Eleita novamente em 1972, a Dr. ․ Glete de 
Alcântara estava apenas começando seu segundo mandato de quatro anos como presidente da ABEn quando adoeceu. O que parecia problema menor, na verdade, era grave. Transferida para seu apartamento, na Praça Buenos Aires, no bairro de Higienópolis, em São Paulo, suas colegas e amigas continuaram visitando-a com regularidade, inclusive religiosas amigas como Madre Domineuc e Irmã Maria Tereza Notarnicola, entre diversas outras (Oguisso, 2010). A Dr. a Glete de Alcântara faleceu no dia 3 de novembro de 1974. O mandato na presidência da ABEn foi concluído pela 1. vice-presidente, Maria da Graça Simões Corte Imperial (Carvalho, 2008).

Mas foi nesse período que a Lei n. ${ }^{\circ}$ 5.905, de 12 de julho de 1973, foi aprovada, criando o Conselho Federal (COFEN) e Regionais (COREn) de Enfermagem no Brasil, e coube a ela encaminhar ao Ministro do Trabalho e Previdência Social, Júlio de Carvalho Barata, a lista tríplice com nomes de enfermeiros de diferentes regiões do Brasil para a nomeação do primeiro plenário do COFEN. Houve tal demora (dois anos) na efetivação da nomeação que o nome do Ministério mudou e também o do ministro, de tal forma que coube a Arnaldo Prieto a nomeação e a posse do primeiro grupo de profissionais para a composição do COFEN, que, afinal, foi implantado em 1975. Nessa ocasião, Maria Rosa de S. Pinheiro foi eleita pelos pares como a primeira presidente do COFEN (Ministério do Trabalho, 1975).

\section{EPÍLOGO}

O velório da Dr. ${ }^{\text {a }}$ Glete de Alcântara ocorreu no salão nobre (atual Auditório Maria Rosa Pinheiro) da Escola de Enfermagem (Carvalho, 1974), vestida com sua beca de professora catedrática. As condolências e homenagens se sucederam, inclusive vindas do próprio CIE, de Genebra. Lamentavelmente, o precoce desaparecimento dessa grande líder da enfermagem constituiu uma lacuna irreparável; porém, ela iluminou muitos caminhos, deixando para todas as gerações de enfermeiras(os) a lição de uma vida dedicada à enfermagem e muitos exemplos de combatividade na luta pelos ideais, principalmente na seara política, discutindo com senadores e deputados sobre o projeto de lei que estava em tramitação, e que resultou na sua aprovação, constituindo-se na Lei n. ${ }^{\circ}$ 5905/1973, que criou o COFEN e os CORENs, conforme já mencionado (Oguisso, 2010).

A ABEn também lhe rendeu homenagens em editorial duplo, no final de 1974. O primeiro texto, assinado por Amália Correa de Carvalho, intitulado Oração de despedida, trata-se do texto lido durante as homenagens finais à docente. A autora destaca a grande perda da companheira de ABEn e da EE-USP, profissional engajada no aperfeiçoamento de seus alunos que, mesmo após sua aposentadoria na EERP-USP, instituição que criou em Ribeirão Preto, sacrificou seu descanso para trabalhar como chefe do Departamento de Orientação Profissional da EE-USP, voltando à primeira escola em que lecionou, destacando-se também sua persistência e abnegação, com ênfase no seu trabalho na ABEn desde 1947, sua presidência na Seção São Paulo durante dois biênios consecutivos, além da presidência nacional em dois mandatos e a presidência da Comissão de Educação da ABEn durante cinco anos. A luta por seus ideais era também a luta pela enfermagem (Carvalho, 1974).

No mesmo editorial, Circe de Mello Ribeiro, presidente da ABEn-SP à época, destaca a Prof. a Glete de Alcântara como uma das "mais importantes figuras da 
enfermagem brasileira". Seu exemplo contribuiu para o avanço da enfermagem com seriedade, liderança e capacidade para lidar com assuntos contraditórios ou polêmicos, promovendo a reflexão dos envolvidos, cujo trabalho buscava ser útil às pessoas na assistência em saúde e cujo valor ético-moral seguiria inspirando os enfermeiros (Ribeiro, 1974).

Na primeira edição de 1975, a Revista da EE-USP também prestou homenagem à docente em seu editorial, destacando a volta à EE-USP após sua aposentadoria em Ribeirão Preto, onde também ministrou as disciplinas de Ética e História da Enfermagem, além de presidir a Comissão de Pós-Graduação e o departamento já mencionado. Ainda na homenagem no editorial, são realçadas as conquistas em seu currículo, como sua participação, a partir de 1966, como membro da Comissão de Peritos de Enfermagem, da OMS. A docente é qualificada como sendo culta e inteligente, de senso de humor fino e competente e que sua perda atingiu toda a enfermagem Brasileira (Pinheiro, 1975).

Glete de Alcântara constitui, até hoje, modelo de liderança e de dedicação à classe e à profissão. Cabe às gerações presentes e futuras a missão de continuar sua obra e sua luta em prol da Enfermagem.

\section{REFERÊNCIAS}

- Alcântara, G. (1952). Currículo de Escolas de Enfermagem: integração da Escola de Enfermagem na sociedade. Anais de Enfermagem, 5(4), 311-9.

- Alcântara, G. (1953). Integración de la escuela de enfermería en la colectividad. Boletin de la Oficina Sanitaria Panamericana, 35(1), 77-83.

- Alcântara, G. (1954). Currículo de escolas de enfermagem. Revista Paulista de Hospitais, Ano 2, 2(6), 21-24.

- Alcântara, G. (1962a). Programa de base para una formación completa de enfermera, 1962. En
Organización Mundial de la Salud. Cuadernos de Salud Publica no. 4. Enfermería de Salud Pública. Problemas y Perspectivas (pp.95-116). Ginebra: WHO.

- Alcântara, G. (1962b). Resenha Histórica da Escola de Enfermagem de Ribeirão Preto. Rev Bras Enferm, 15(2), 88-91.

- Alcântara, G. (1963a). Memorial. 1963. Concurso para Docência. Faculdade de Medicina de Ribeirão Preto São Paulo: Universidade de São Paulo.

- Alcântara, G. (1963b). A enfermagem moderna como categoria profissional: obstáculos à sua expansão na sociedade brasileira. (Tese de cátedra). Escola de Enfermagem de Ribeirão Preto. Ribeirão Preto: Universidade de São Paulo.

- Alcântara, G. (1964). Curriculum vitae. Rev Bras Enferm, 17(1/2), 42-7.

- Alcântara, G. (1970). Apresentação da enfermeira paulista. Rev Esc Enferm USP, 4(1-2), 125-30.

- Angerami, E.L.S. \& Pelá, N.T.R. (1976). Glete de Alcântara: vida e Obra. São Paulo: Revista dos Tribunais.

- Atas Escola de Enfermagem da USP. (1953). Atas do Corpo Docente-1948 a 1953. São Paulo: Pasta arquivada na Diretoria Acadêmica da Escola de Enfermagem da USP.

- Bardin, L. (2011). Análise de conteúdo. São Paulo: Edições 70.

- Bridges, D.C. (1967). A history of the International Council of Nurses 1899-1964: the first sixty-five years. London, England: Pitman Medical Publishing.

- Brown, E.L. (1949). Enfermagem para o futuro. Relatório preparado para o conselho nacional de enfermagem dos Estados Unidos. São Paulo: Serviço Especial de Saúde Pública.

- Carvalho, A.C. (1974). Oração de Despedida Rev Bras Enferm, 27(4), 405-407.

- Carvalho, A.C. (1980). Escola de Enfermagem da USP: resumo histórico 1942-1980. Rev Esc Enferm USP, 14(supl.), 209.

- Carvalho, A.C. (2008). Associação Brasileira de Enfermagem-Documentário, 1926-1976，2.․ edição, Brasília: ABEn.

- Ferreira-Santos, C.A. (1976). A Enfermagem moderna como categoria profissional. Obstáculos à sua expansão na sociedade brasileira. En Angerami, E.L.S., Pelá, N.T.R. Glete de Alcântara: vida e Obra (pp.55-71). São Paulo: Revista dos Tribunais.

- Instituto Brasileiro de Geografia e Estatística [IBGE]. (2000). Tendências Demográficas: uma análise da população com base nos resultados dos censos demográficos de 1940 e 2000. Recuperado de https://biblioteca.ibge.gov.br/visualizacao/livros/li v34956.pdf. 
- Le Goff, J. (1989). Comment écrire une biographie historique aujourd'hui? Le Débat, 2(54), 48-53.

- Mendes I.A.C. (1993). Escola de Enfermagem de Ribeirão Preto da Universidade de São Paulo: quatro décadas. Rev Latino-Am Enferm, 1 (n. esp.),1 7-24.

- Mendes, I.A.C., Leite, J.L., Leite, J.L. y Trevizan, M.A. (2002). A REBEn no contexto da história da enfermagem brasileira: a importância da memória de D. a Glete de Alcântara. Rev Bras Enferm, 55(3), 270-4.

- Oguisso, T. (novembro, 2010). Convivências e Lembranças da Profa. Dra. Glete de Alcântara. Em Luchesi, L.B. (Coord.), 1. ํㅡㄹ Centenário de Nascimento: a vida e obra de Glete de Alcântara e a EERP-USP, Laboratório de Estudo em História da Enfermagem-LAESHE, Direção, Centro de Memória e Comissão de Cultura e Extensão da Escola de Enfermagem de Ribeirão Preto. Ribeirão Preto: LAESHE.

- Oguisso, T. Apresentação (2014). En Oguisso T. (org). Trajetória histórica da Enfermagem (pp. 11-15. Barueri: Manole.

- Pinheiro, M.R.S. (1975). Editorial: Glete de Alcântara: in memoriam. Rev Esc Enferm USP, 9(1), 7-8.

- Pinheiro, M.R.S. (1976). Formação profissional. En
Angerami, E.L.S., Pelá, N.T.R. Glete de Alcântara: vida e obra (pp. 3-18). São Paulo: Revista dos Tribunais.

- Ribeiro, C.M. (1974). Homenagem póstuma. Rev Bras Enferm, 27(4), 408.

- Sanna, M.C. (2011). Biografia. En Oguisso, T., Campos, P.F.S., Freiras, G.F, (Orgs.). Pesquisa em História da Enfermagem (pp. 301-38). Barueri, SP: Manole.

- Secaf, V. \& Costa, H.C.B.A. (2007). Enfermeiras do Brasil: história das pioneiras. São Paulo: Martinari.

- Ministério do Trabalho. (1975). Conselho Federal de Enfermagem-Enfermagem: criação e instalação de sua autarquia profissional (Relatório apresentado pelos membros designados pela Portaria n. 3059, de 0503-1975, do Exmo. Ministro do Trabalho, baixada de acordo com o disposto no art. 21, da Lei 5905, de 12-07-1973. Gestão, 23-04-1975 a 22-04-1976. Anexo 2, p. 37). Brasília: Ministério do Trabalho.

- Universidade de São Paulo [USP]. (1951). Parecer da Comissão de Ensino e Regimentos sobre a instalação da Faculdade de Medicina de Ribeirão Preto (Relatório do Processo No. 51.1.3320-1-7, Arquivo da Universidade de São Paulo). São Paulo: Universidade de São Paulo. 